\title{
International Undergraduate Medical Student in China and the Potentiality of Using PBL method in the Integrated Organ/System Curriculum
}

\author{
${ }^{\#}$ Sudirman Fakhruddin Masse ${ }^{1,2}$, Huibing Tan ${ }^{1 *}$ \\ ${ }^{1}$ Department of Anatomy, Jinzhou Medical University, Jinzhou, Liaoning 121001, China \\ ${ }^{2}$ International college, Jinzhou Medical University, Jinzhou, Liaoning 121001, China \\ \# Undergraduate from Indonesia \\ * Correspondence: Department of Anatomy, Jinzhou Medical University, Jinzhou, Liaoning \\ 121001,China,davidtanhb@foxmail.com
}

\begin{abstract}
The advance of the medical field in the 21st century has influenced the development of many innovations, including in medical education. PBL (problem-based learning) is one of the pedagogical approaches that has been studying and implementing worldwide to attract medical students' attention with their learning style and learning environment. China is the most significant "receiver" country of foreign students in Asia, and clinical medicine is one of the most chosen majors for undergraduate. In China, PBL has been implementing in some schools, but mostly with the local students and only a few implementations to the international students. International medical students in China faced a variety of challenges during their studies. In this review paper, we give the solution to adapt to the challenges by focusing on the implementation the integrated organ/system curriculum/syllabus with the PBL method to the school system with the support of the school stakeholders and students' role.
\end{abstract}

Keywords: medical education, pedagogy, international student, problem-based learning, integrated organ/system, China

\section{Outline}

a. Why does the transformation of medical education be necessary?

b. Why does PBL as an optional for the transformation of medical education strategy?

c. How does the implementation PBL in China?

d. Why does PBL can improve the quality of International graduation of medical education in China?

e. What strategy will be potentially adopted in the PBL method?

1. Why does the transformation of medical education be necessary?

The incredible advances of global innovation in the recent decade have influenced the medical field from medical knowledge, medical technology, and pedagogy system in medical education. In the $21^{\text {st }}$ century, technology has been a significant catalyst for much of the change, especially for the "Millennial Learner" with all of the "cutting edge" devices and various platforms for learning ${ }^{[1]}$.

With this advance, a medical graduate must be a lifelong learner to provide timely, efficient, and stateof-the-art patient care ${ }^{[2]}$. Lifelong learning is continuous, collaborative, self-directed, and active 
learning. Moreover, sufficient practical skills also necessary to become effective lifelong learners ${ }^{[3]}$.

The increasing accessibility of medical information which helps the learning and teaching environment is necessary for the medical education to innovate the system which can create a better quality of the future graduate doctors with the skills of critical thinking, effectively communicate and work in interprofessional teams in the digital workplace by adding the innovation to student's learning styles, approaches and curriculum mapping ${ }^{[4,5]}$

\section{Why does PBL as an optional for the transformation of medical education strategy?}

The role of the student as a proactive learner and the teacher as the facilitator, the student engagement, the learning style and the learning environment ${ }^{[3,6-8]}$ are the general factors that generate the necessity of the transformation from traditional teaching method which is an instructor-focused environment or lectured-centered to be more student-centered in the active learning environment ${ }^{[1,6-12]}$. Additionally, the learning approach is strongly influencing the learning outcome of medical education. Deep approach is the most desirable and successful approach in which the students have the intention to understand the material or object ${ }^{[5]}$

PBL (Problem-Based Learning) is the popular learning strategy studied in recent decades in medical education was first implemented in 1969 by McMaster University medical school, Canada, and it is now globally implementing by many medical schools $^{[13,14]}$. PBL, as the student-centered instructional approach is technically discussing the relevant problem in a small group under the guidance of a teacher (i.e., tutor), can help to develop lifelong learning and independent learning skills to approach the deep learning ${ }^{[15,16]}$.

The goal of PBL was to improve student's abilities to solve clinical problems ${ }^{[13]}$. Following the progress by implementing globally, other benefits of PBL have been shown from the ability to enhance the critical thinking, improving the students' interest and a better understanding of subjects, effective teamwork, improving the doctor-patient relationship, and promote students' knowledge retention by linking basic medical science to the clinical practice. Furthermore, PBL also improved the students' preparedness for clinical practice, social learning practice, and improved students' debating and leadership skills ${ }^{[14,17,18]}$.

\section{How does the implementation PBL in China?}

Since the first implementation in McMaster university, it is now following by the number of medical schools around the world, including in China. The implementation of PBL methods in China began in the mid-1980s and then increased from 14 in 2000 to 474 in $2011^{[19]}$.

PBL study in China becomes more accessible to improve teaching methods and clinical applications [19-24]. For instance, in Nanjing Medical School has adopted PBL in preventive medicine education since 2012 and showed a variety of outcomes such as motivating in learning, problem solved skill, collaborative skill and critical thinking ${ }^{[21]}$. The implementation of digital PBL cases in the Ophthalmology courses at China Medical University also showed the improvement in educational quality and effectiveness as well as to stimulate students' learning interest, diagnosis, and problem-handling skills. ${ }^{[27]}$ In the Third Military Medical University, the implementation of hybrid-PBL in the large classroom had a positive result not only to the students' fundamental knowledge improvement but also problem-solving skills ${ }^{[25]}$.

The effectiveness of the PBL implementation among Chinese medical students both preclinically and clinically suggested the opportunity for the transformation of medical education from the traditional teaching method to more studentcentered $^{[22,26]}$.

\section{Why does PBL can improve the quality of International graduation of medical education in China?}

China is one of the significant contributor countries for international students worldwide to study and become the third-ranked destination for International college student following USA and UK which means that China becomes the most significant 
host for international student in $\mathrm{Asia}^{[27,28]}$

Clinical medicine is one of the highest portion of international students' choice in China ${ }^{[27]}$. However, the international medical student meets some challenges in studying medicine in China, especially for English-medium medical program. It was identified that the challenge of the implementation of the English-medium medical program strongly affected by the social and cultural factors as well as the limited English proficiency of teachers and learners $^{[29]}$.

According to Yang's study (2019) ${ }^{[29]}$, some of the challenges in the English-medium medical program are (1) Insufficient or inappropriate English-medium Instruction resources (2) Unsatisfactory teaching efforts (3) Inadequate classroom interaction and (4) failure to teach medical humanities issues. To address those challenges, students tend to add more effort outside the class to self-study, such as finding their resources, turning to study groups and peers for help, and interact with the teachers directly by using the Chinese language outside the class activity. ${ }^{[29]}$

To find the solution, the implementation of the PBL system is one of the solutions that can help to adapt to this condition ${ }^{[29]}$. As described previously, PBL, as the student-centered teaching approach, can encourage students to learn and promote more group discussion, which is necessary for the international medical students in China to match their learning style and learning environment.

One of the examples of the implementation of PBL in the international medical education of China is at Dalian Medical University. By Introducing a Hybrid-PBL curriculum in the Biochemistry course with the combination of PBL curriculum with conventional lectures have given the positive impacts for students, from self-directed learning skills, problem-solving skills, group collaboration skills, ability to work independently, presentation skills, interpersonal skills, to public speaking skills. Comparing to the non-PBL groups, the PBL group students tend to more satisfied with the implementation of PBL in the teaching system ${ }^{[30]}$.

In our university, the organ system-centric combined with PBL teaching mode has been conducted since $1991^{[31]}$. China medical education also offers many after-class programs, for example career training programs of scientific research and career development for Undergraduates (Undergraduate Innovation and Entrepreneurship Training Programs). Many local and international students can join scientific project in science research lab or establish student business in the JZMU. Student scientific project competitions and student business plan competitions are also available for undergraduates. The PBL as a pedagogical approach is integrated in systematic teaching program in the medical education in China. Besides PBL teaching approach, some after-class activities or workshops and training programs are also available, for example journal club (Supplementary Figure 1) and research, workshop or lab research program (Figure 1). Many students worked with senior undergraduates, postgraduate, principal investigator or professor in the research lab during a school break in summer and winter. Some senior undergraduates can master experimental techniques and skills. For experimental animal, students can work for animal dandling, animal feeding, behavior tests and learn preparation solution, preparation of tissues of the brain and spinal cord, sectioning by means of cryostat microtome, common tissue staining such as immunocytochemistry and NADPH diaphorase as well as software for scientific research staining in Department of Anatomy in JZMU. The students who participated scientific research could publish research article as co-authors when their contribution was proper for publishing. We believe that the publications are beneficial for application of postgraduate program and job hunting for medical professional (Supplementary reference).

However, to encourage the student's interest to learn is not only influenced by the students' role, but also it is necessarily provided from the institutional and faculty development support, and with the wellprepared strategies for student self and peer group learning ${ }^{[29]}$.

As the PBL has been implemented in some medical schools in China, especially for Chinese students, it is also an excellent opportunity to initiate the transformation of the international medical education system into PBL. 


\section{What strategy will be potentially adopted in the PBL method?}

Generally, international undergraduate students are taking MBBS (Bachelor of Medicine, Bachelor of Surgery) major in medical school in China which is mainly focusing on basic and preclinical courses and it is dominated by classroom-teaching style with lectured-centered in their first five years (total is six years) such as showing in Jinzhou Medical University $(\mathrm{JZMU})^{[32]}$.

A study in Jinan University Medical School showed that lower scores achieved by international students compared to Chinese students; one of the reasons is that lack of focus on the contents were taught in the class. Thus, the students tend to spend more time mastering the content independently outside the class. The related factor of this issue is that international students are selecting the subjects to learn based on their interests. This is associated with the demand of students to pass the exam for their national licensing examination and internship ${ }^{[33]}$.

Reflecting on our learning experience in JZMU, most students also choose to self-study or group study; therefore, the students tend to invest more extra time in studying and result in decrease resting and leisure time.

To address the challenge of students' learning environment, especially for the basic and preclinical course, implementing the integrated organ/system curriculum to the school system during the early years is one of the best options to choose with focusing on the PBL method. The aim of this strategy is to support the clinical years later with the strong basic science ${ }^{[34]}$, such as showing by implementation in the New Medical College in Saudi Arabia ${ }^{[35]}$. Furthermore, this approach also might help international students to prepare for their national licensing exams in the future.

Some of the basic science course implemented this system is reported with positive outcomes to the students, such as showing in anatomy and pharmacology course $\mathrm{e}^{[36,37]}$. Therefore, investing time to prepare this strategy is necessary, especially during the basic and preclinical courses ${ }^{[38]}$. The detailed mechanism is provided in the illustration below (Figure 2 and Table 1)

However, rearranging or readapting the existing curriculum or school system from traditional method to PBL method with "integrated organ/system curriculum" will meet some challenges in medical education, such as the need to acknowledge about PBL method to the faculty such as the teachers in each department, school staffs, and the students. Furthermore, it also needs more training for the teachers to implement the PBL method with the wellprovided integrated organ/system syllabus. Therefore, it will need some modifications in the school system.

In order to get successful outcomes in the early implementation of this system, adapting with the selected subjects and with selected batch or class maybe can be tried first, and then later will be evaluated to observe the progress of the system

\section{Discussion}

As the medical pedagogy, PBL is the innovation that has been practiced by the number of medical schools worldwide. This learning approach and strategy show many positive impacts on future medical professionalism to meet the advance of today's medical field. PBL cultivates the student's interest to learn by a deep understanding and more critically think, high problem-solving skills, and improve the autonomous learning of students in learning activities ${ }^{[13,14,17]}$.

Although some schools have successfully adopted PBL in their school system, it was not an easy transformation. The challenges in medical education always exist, especially in China. Therefore, it needs more time and support from the stakeholders and students' awareness

The successful implementation of PBL for local students in some medical schools is well-reported. However, our literature findings showed only a few implementations to international medical students. Thus, the more implementation of international medical students is necessary to support the transformation of the traditional teaching method to more student-centered.

The successful implementation of PBL for local 
students in some medical schools is well-reported. However, our literature findings showed only a few implementations to international medical students. Thus, the more implementation of international medical students is necessary to support the transformation of the traditional teaching method to more student-centered and more studies are required in other courses, both clinically and preclinically, to promote the transformation.

\section{Conclusion}

This review article describes the importance of the transformation of medical education from the traditional teaching method to more student-centered. The challenges of international medical students in China suggest the potentiality to implement the PBL system into the international medical education system as the method to adapt to students' learning styles and learning environments by support from the school stakeholders and students' participation. This transformation can be started from the reformation or rearranging the traditional curriculum/syllabus system to a more integrated organ/system curriculum/syllabus with the PBL method in basic and preclinical courses.

\section{ACKNOWLEDGMENTS}

This work was supported by grants Research Start-Up Grant for New Science Faculty of Jinzhou Medical University (173514017) and Liaoning Student Training Programs of scientific research and career development for Undergraduates, (201410160007 Undergraduate Innovation and Entrepreneurship Training Programs).

\section{CONFLICT OF INTERESTS}

The authors have no conflicts of interest to declare.

\section{References:}

1. Mulkern JB. Navigating medical education reform: charting a course through changing landscapes of technology, pedagogy, and content [Internet].
2019; Available from:

https://hdl.handle.net/2144/36010

2. Panda M, Desbiens NA. An "education for life" requirement to promote lifelong learning in an internal medicine residency program. J Grad Med Educ 2010;2(4):562-5.

3. Collins J. Lifelong learning in the 21st century and beyond. Radiographics 2009;

4. Kecskes Z, Mitchell I. Introducing a new series on innovations in medical education. Med. J. Aust.2017;206(1):13.

5. NEWBLE DI, ENTWISTLE NJ. Learning styles and approaches: implications for medical education. Med Educ [Internet] 1986;20(3):162-75. Available from: https://doi.org/10.1111/j.1365-2923.1986.tb01163.x

6. Louie B, Byrne N, Wasylenki D. From feedback to reciprocity. Developing a student-centered approach to course evaluation. Eval Health Prof 1996;19(2):231-42.

7. Kim K-J, Hwang J-Y. Characteristics of medical teachers using student-centered teaching methods. Korean J Med Educ 2017;29(3):187-91.

8. Rezende-Filho FM, da Fonseca LJS, Nunes-Souza V, Guedes G da S, Rabelo LA. A student-centered approach for developing active learning: the construction of physical models as a teaching tool in medical physiology. BMC Med Educ 2014;14:189.

9. Naranjo A, de Toro J, Nolla JM. The teaching of rheumatology at the University. The journey from teacher based to student-centered learning. Reumatol Clin 2015;11(4):196-203.

10. Al Shehri MY. Current issues in medical education. West Afr J Med 2003;22(4):329-33.

11. Hsih KW, Iscoe MS, Lupton JR, Mains TE, Nayar SK, Orlando MS, et al. The Student Curriculum Review Team: How we catalyze curricular changes through a student-centered approach. Med Teach 2015;37(11):1008-12.

12. Yengo-Kahn AM, Baker CE, Lomis AKD. Medical Students' Perspectives on Implementing Curriculum Change at One Institution. Acad Med 2017;92(4):455-61.

13. Gwee MC-E. Problem-based learning: a strategic learning system design for the education of healthcare professionals in the 21 st century. Kaohsiung J Med Sci 2009;25(5):231-9.

14. Fan C, Jiang B, Shi X, Wang E, Li Q. Update on research and application of problem-based learning in medical science education. Biochem Mol Biol Educ 2018;46(2):186-94.

15. Dolmans DHJM, Loyens SMM, Marcq H, Gijbels D. Deep and surface learning in problem-based learning: a review of the literature. Adv Health Sci Educ 
Theory Pract 2016;21(5):1087-112.

16. Groves M. Problem-based learning and learning approach: is there a relationship? Adv Health Sci Educ Theory Pract 2005;10(4):315-26.

17. Preeti B, Ashish A, Shriram G. Problem Based Learning (PBL) - An Effective Approach to Improve Learning Outcomes in Medical Teaching. J Clin Diagn Res 2013;7(12):2896-7.

18. Ginzburg SB, Deutsch S, Bellissimo J, Elkowitz DE, Stern JN, Lucito R. Integration of leadership training into a problem/case-based learning program for firstand second-year medical students. Adv Med Educ Pract 2018;9:221-6.

19. Zhang Y, Zhou L, Liu X, Liu L, Wu Y, Zhao Z, et al. The Effectiveness of the Problem-Based Learning Teaching Model for Use in Introductory Chinese Undergraduate Medical Courses: A Systematic Review and Meta- Analysis. PLoS One [Internet] 2015;10(3):e0120884. Available from: http://journals.plos.org/plosone/article/file?id=10.13 71/journal.pone. $0120884 \&$ type $=$ printable

20. Li J, Li QL, Chen ML, Xie HF, Li YP, Chen X. Comparison of three problem-based learning conditions (real patients, digital and paper) with lecture-based learning in a dermatology course: A prospective randomized study from China. Med Teach 2013;35(2).

21. Ding X, Zhao L, Chu H, Tong N, Ni C, Hu Z, et al. Assessing the effectiveness of problem-based learning of preventive medicine education in China. Sci Rep 2014;4.

22. Wang J, Xu Y, Liu X, Xiong W, Xie J, Zhao J. Assessing the effectiveness of problem-based learning in physical diagnostics education in China: A meta-analysis. Sci Rep 2016;6.

23. Xue H, Qian J, Wang L, Yuan X, Chen Y, Wu W, et al. 3C3R Modified PBL Pediatric Teaching of Chinese Medical Students. PLoS One 2013;8(5).

24. Tang F, Chen C, Zhu Y, Zuo C, Zhong Y, Wang N, et al. Comparison between flipped classroom and lecture-based classroom in ophthalmology clerkship. Med Educ Online [Internet] 2017;22(1):1395679. Available from: https://www.tandfonline.com/doi/full/10.1080/10872 981.2017.1395679

25. Lian J, He F. Improved performance of students instructed in a hybrid PBL format. Biochem Mol Biol Educ 2013;41(1):5-10.

26. Ma Y, Lu X. The effectiveness of problem-based learning in pediatric medical education in China: A meta-analysis of randomized controlled trials. Medicine (Baltimore) 2019;98(2):e14052.

27. Wen $\mathrm{W}, \mathrm{Hu}$ D. The Emergence of a Regional
Education Hub: Rationales of International Students' Choice of China as the Study Destination. J Stud Int Educ [Internet] 2018;23(3):303-25. Available from: https://doi.org/10.1177/1028315318797154

28. Jiani MA. Why and how international students choose Mainland China as a higher education study abroad destination. High Educ 2017;

29. Yang M, O'Sullivan PS, Irby DM, Chen Z, Lin C, Lin C. Challenges and adaptations in implementing an English-medium medical program:a case study in China. BMC Med Educ 2019;19(1):15.

30. Yan Q, Ma L, Zhu L, Zhang W. Learning effectiveness and satisfaction of international medical students: Introducing a Hybrid-PBL curriculum in biochemistry. Biochem Mol Biol Educ 2017;45(4):336-42.

31. 席焕久, 秦书俭, 李红玉, 高书杰. “以器官系统为中 心”医学基础课程模式改革研究. 医学教育 Medical Education ( China) 2003, Oct, 5.

32. University JM. The Foreign Students Training Program of Jinzhou Medical University (Abstract)

[Internet]. Available from: http://ciejzmu.com/jzmu/index.php/academictraining-program/

33. Ming-ya Zhang, Guang Wang, Xin Cheng XY. Investigating the medical study of overseas students at Jinan University Medical School. Int J High Educ 2017;6(4).

34. Schmidt $\mathrm{H}$. Integrating the teaching of basic sciences, clinical sciences, and biopsychosocial issues. Acad Med 1998;73(9 Suppl):S24-31.

35. El-Naggar MM, Ageely H, Salih MA, Dawoud H, Milaat WA. Developing an integrated organ/system curriculum with community-orientation for a new medical college in jazan, saudi arabia. J Family Community Med 2007;14(3):127-36.

36. Sivam SP, Iatridis PG, Vaughn S. Integration of pharmacology into a problem-based learning curriculum for medical students. Med Educ 1995;29(4):289-96.

37. Brooks WS, Woodley KTCP, Jackson JR, Hoesley CJ. Integration of gross anatomy in an organ systembased medical curriculum: strategies and challenges. Anat Sci Educ 2015;8(3):266-74.

38. Ibrahim ME, Al-Shahrani AM, Abdalla ME, Abubaker IM, Mohamed ME. The Effectiveness of Problem-based Learning in Acquisition of Knowledge, Soft Skills During Basic and Preclinical Sciences: Medical Students' Points of View. Acta Inform medica AIM J Soc Med Informatics Bosnia Herzegovina Cas Drus za Med Inform BiH 2018;26(2):119-24. 
Supplementary reference:

The name of the First author Sudirman Fakhruddin Masse listed in a preprint:

Yunge Jia, Yinhua Li, Wei Hou, Fuhong Li, Haoran Sun, Xianhui Wu, Xiaoxin Wen, Zicun Wei, Chenxu Rao, Ximeng $\mathrm{Xu}$, Sudirman Fakhruddin Masse, Kuerbanjiang Abulikim,
Sheng-fei Xu, Guang-hui Du, Huibing Tan. A pathway of NADPH diaphorase positivity between central canal and pial surface at anterior fissure in spinal cord: Supra fissure area with hypothesis configuring from dog, rat, monkey and pigeon, bioRxiv 2020.05.02.074450; doi: https://doi.org/10.1101/2020.05.02.074450

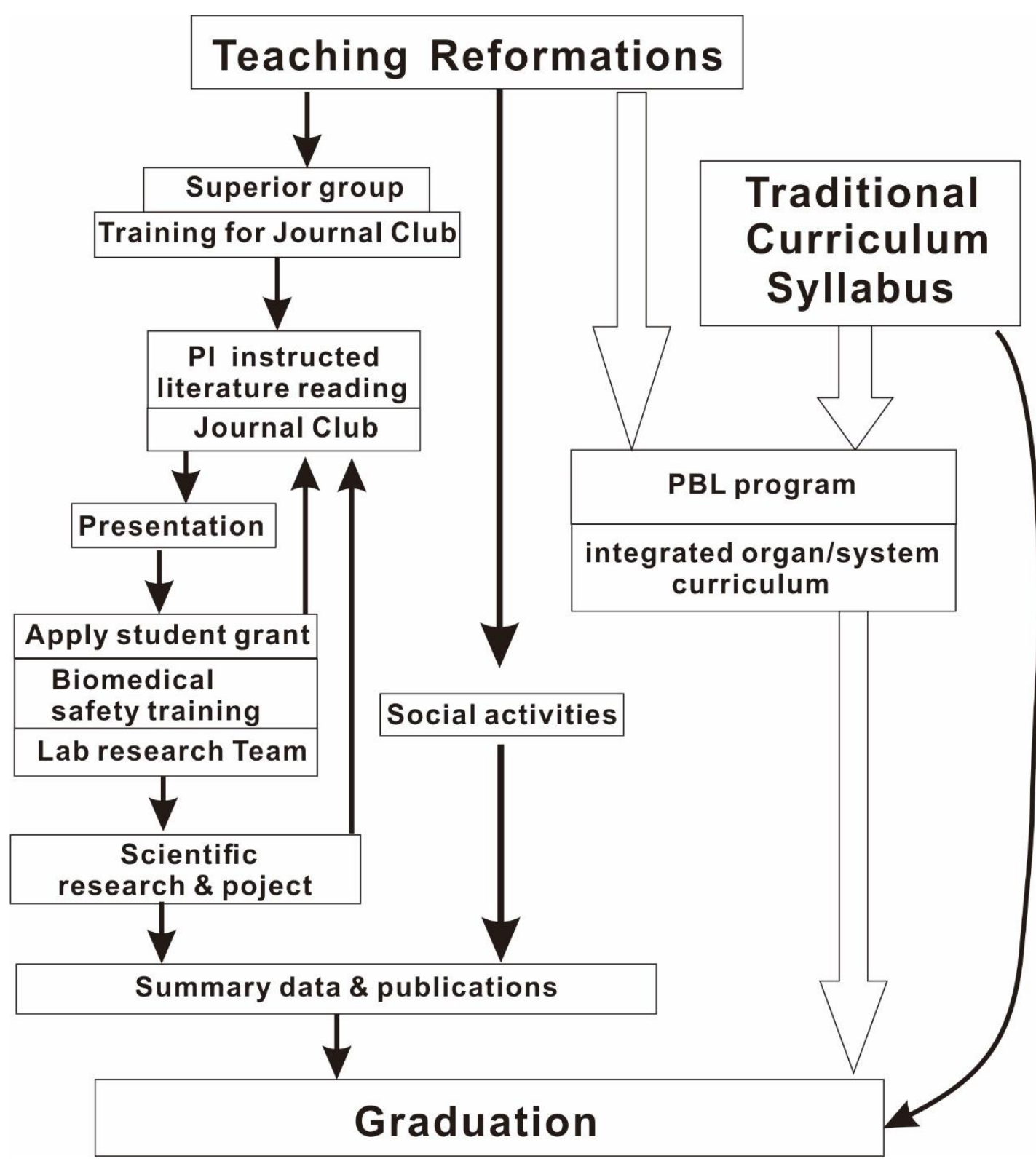

Figure 1. The flow chart for the undergraduate scientific training program in Neuroscience Lab in Department of Anatomy and teaching program in the JZMU 


\section{ISSUE}

Mismatch of Learning Environment of International Medical students with the Learning system

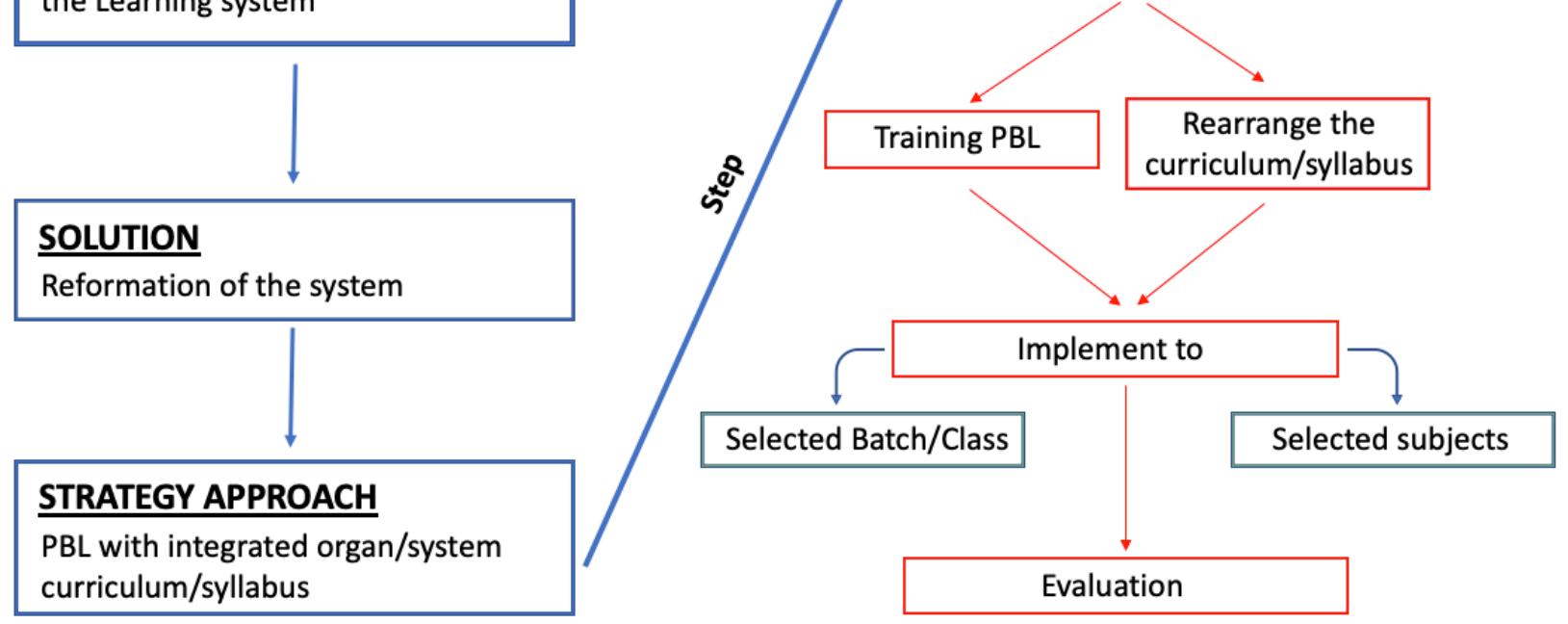

Figure 2. The strategy of implementing "integrated organ/system curriculum/syllabus" with PBL method to international medical students

Table 1. The outline steps of PBL method in the integrated organ/system curriculum

\begin{tabular}{|c|c|}
\hline Steps & Description \\
\hline Group and Tutor Collection & $\begin{array}{l}\text { - Group consists of small group of students ( } 6 \text { to } 7 \text { students) } \\
\text { - The teacher is assumed to be a tutor (also known as the moderator or } \\
\text { facilitator) }\end{array}$ \\
\hline Study material collection & $\begin{array}{l}\text { - The faculty/school department select the specific subject to integrate } \\
\text { into the PBL method } \\
\text { - The faculty/school department provides the core principle } \\
\text { descriptions of the chosen subject }\end{array}$ \\
\hline Tutorial session description & $\begin{array}{l}\text { - The faculty/school department introduce the PBL system to the group } \\
\text { and the tutor } \\
\text { - The faculty/school department share a protocol or detail procedures } \\
\text { about the PBL method from the available core principle descriptions of } \\
\text { the chosen subject }\end{array}$ \\
\hline Self-learning and material collection & $\begin{array}{l}\text { - The tutor will instruct and give a brief introduction of the selected } \\
\text { topic to the group } \\
\text { - The group will do self-learning or self-study in the given period with } \\
\text { using all available material formats (e.g., internet, video, or literature) }\end{array}$ \\
\hline Assessment & $\begin{array}{l}\text { - The tutor will evaluate the students' performance in the group, } \\
\text { including knowledge mastering by using question format, such } \\
\text { multiple choice question or by using group presentation method }\end{array}$ \\
\hline
\end{tabular}

